\title{
Effective ERP Web Application for Construction
}

\author{
Mahind Rupali N. ${ }^{1}$, Patil Gaurav M. ${ }^{2}$ \\ Professor, Computer Science \& Engg, DACOE, Karad, India ${ }^{1}$ \\ Student, Computer Science \& Engg, DACOE, Karad, India ${ }^{2}$
}

\begin{abstract}
Inventory Management Software is a computer based system for tracking inventory levels, orders, sales and deliveries. It can be also used in the manufacturing industry to create a work order, bill of materials and other production related documents. Companies use inventory management system to avoids product overstock and outage. Companies often use inventory management system to reduce their carrying cost. The software is used to track the products and parts as they are transported from a vendor to a warehouse, between warehouse and finally to retail location to directly to the customer. This software is also useful in picking, packing and shipping items from warehouse. It is useful to avoiding missing out on sales due to out-of-stock situation. The system that we are developing is whole based system.
\end{abstract}

Keywords: Web Technology, Inventory, Stock, Performance.

\section{INTRODUCTION}

In "Web Based Inventory System for Construction" a admin can use histher Manage privileges online without any difficulty. HelShe has to fill a registration form to register himselflherself. All the entries is checked in the database which has already all information about the administrator. If all the entries are correct then a User Id and Password is given to the sub admin, by using that User ID and Password helshe can use histher rights. If conditions are wrong then that entry will be discarded efforts reduces. Admin can do registration of sub admin and sub admin can register to the user. This system contain management of the construction related inventory and maintaining the stock. Traditional System, in which Manager take place with traditional rules, such as papers, and register that maintain the use of material and maintaining the stock. That system takes more time and requires human's resources. False Manager introduce the problems in construction system was inefficient.

To reduce the problem of traditional construction inventory system, new technique was introduced which reduces work on paper, extra time required, wastage of money \& resources, more human efforts .The intelligent made simple software for construction system in which all information stored on database .To make fulfill featured software. The calculation of vote easily handled \& result displayed to users in very few seconds. After that web solution was aroused for inventory.

\section{LITERATURE SURVEY}

There no current system in use, all the work is done by the means of documents So we are developing this system. So that the paper work and work time could be saved.

We referred previously deployed system Web Based Inventory Management System used in West Virginia State Police.[1]
This describes the conversion of a DOS-based database system to meet very specific web-based database requirements of the West Virginia State Police. The need for conversion was proposed by the West Virginia State Police in January of 2007. The conversion process given here: allows for normalization of all data; to make the process of inventory management easier for employees of the West Virginia State Police (WVSP); enumerates inventory management problems currently being faced by the WVSP; present a brief explanation of databases and the database model being used; and provides the initial requirements, specifications for this system These requirements for the new database system will minimize current problems faced by the WVSP. A first prototype was developed and is presented as well as part of this thesis.

Syed Jamal Abdul Nasir bin Syed Mohamad, Nurul Nadia Suraidi, Nabihah Amirah Abd. Rahman, and Raja Durratun Sakinah Raja Suhaimi findings of an applied research on inventory management at a textile chain store in Malaysia. It specifically examined the relationship between inventory management and company's performance. This paper also provides recommendation to the company and for further research.[2]

Tom Jose V, Akhilesh Jayakumar, Sijo M T analyzing different inventory control techniques for efficient inventory management system. In this they used $A B C$ analysis and FSN analysis. The ABC system is a widely used classification technique to identify various items of inventory for purposes of inventory control. All the items in the inventory are not required at the same frequency. Some are required regularly, some occasionally and some very rarely. FSN classifies items into Fast moving, Slow moving and Non-moving. [3]

Abisoye Opeyemi A., Boboye Fatoba, Abisoye Blessing O has designed a Computerized Inventory Management 
IARJSET

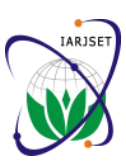

International Advanced Research Journal in Science, Engineering and Technology

National Conference on Innovative Applications and Research in Computer Science and Engineering (NCIARCSE-2017)

AGTI's Dr. Daulatrao Aher College Engineering, Vidyanagar Extension, Karad

Vol. 4, Special Issue 4, January 2017

System to ascertain stock level of a supermarket, when to C) Projects :

order for more products, keep status and updates of This module is interact with all other modules from all transactions, thereby helping managerial decisions, users. It maintains Procurements of projects, current progress level and stock taking. The main method used projects status, which resources are used and also project for this research work is interview. Data were collected details.

from 5 heterogeneous supermarkets and used as a tool for obtaining facts. [4]

D) Users:

Toktay, Wein and Zenios use a queuing network model, This module contains information about all the registered which allows for considerable flexibility in modeling users which are authorized for functionalities. Using this production and distribution facilities within the supply module Site Supervisor updates the working status of chain, and they focus on the statistical aspects of the project into the system and also request for different problem, by dynamically estimating the probability that resources (Materials, Machineries, and Humans) to the sold cameras are returned, the delay of returned cameras, Store.

and the number of cameras that have been sold and will be returned at some future time. Although the paper is written in a problem-specific manner, the model and methods used here are generic and can be adapted to other remanufacturing settings.[5]

Serhii ZIUKOV analyzes possible parameters of existing models of inventory control. An attempt is made to provide an up-to-date review of existing literature, concentrating on descriptions of the characteristics and types of inventory control models that have been developed.[6]

\section{III.DESIGN AND PROPOSED WORK}

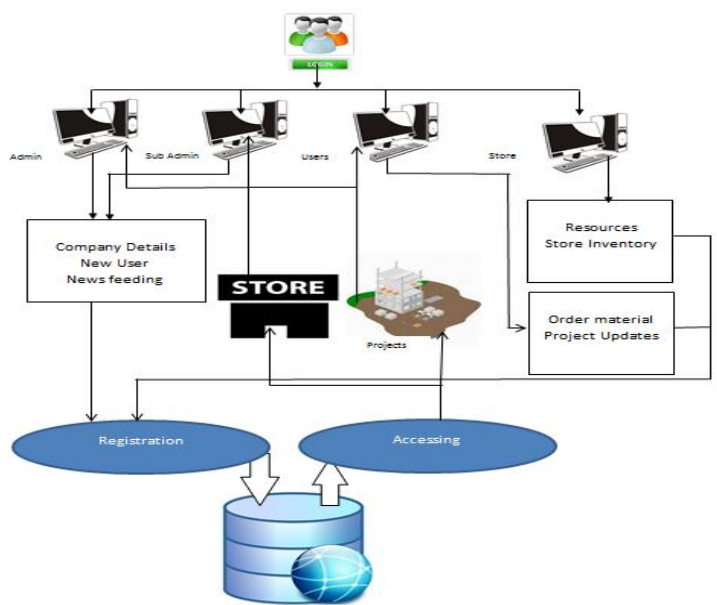

Fig 1. System Architecture

There are several modules are present in this system. Functionalities of this modules are given below

\section{A) Admin:}

Admin having functionalities are:

- Register Company Details

- Create New Users

- Edit All Users Information

- Edit Own User Information.

- Edit Access Secured Settings.

- Monitor The Project Status.

B) Sub Admin:

Sub Admin having same functionalities as the Admin.

\section{E) Store:}

This module operates from the Store Operator user. It maintains all the details about available resources with allocated resources and free resources

It gives response to Site Supervisor with delivery of resources at specific project.

\section{IV.WEB TECHNOLOGY}

The users of this project are belongs from different locations and can access this system on any electronic devices like laptop PCs Tablets etc. for this purpose we implement this system in web technology.

\section{RESULT}

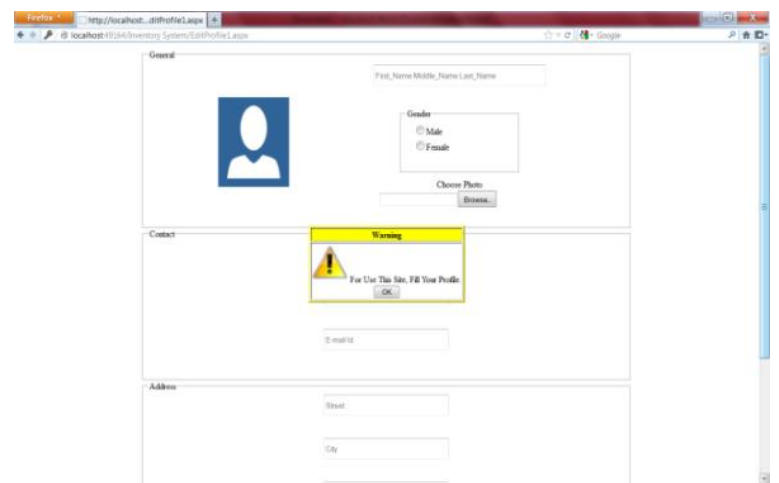

Fig 1: Login Page

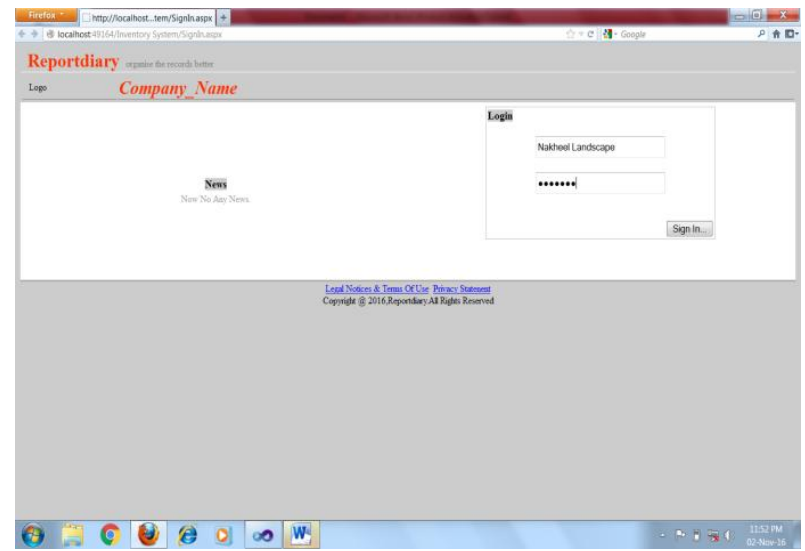

Fig 2. Profile Warning 
IARJSET

Vol. 4, Special Issue 4, January 2017

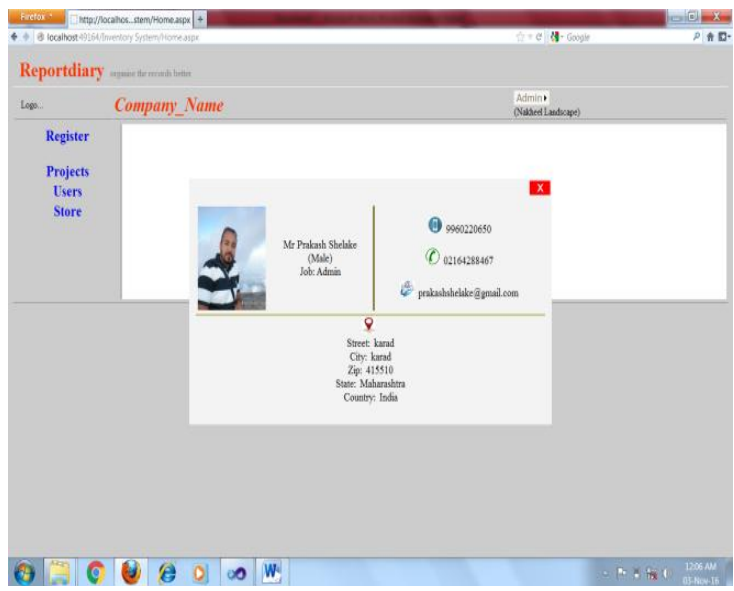

Fig 3 About

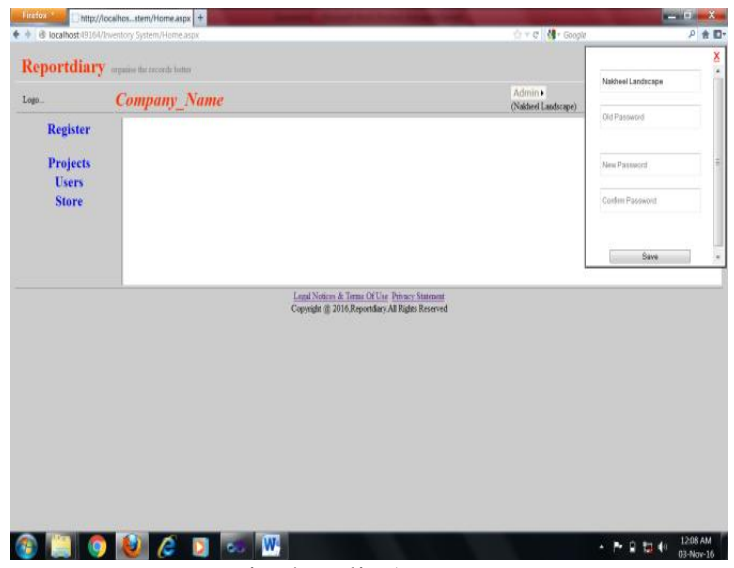

Fig 4. Edit Account

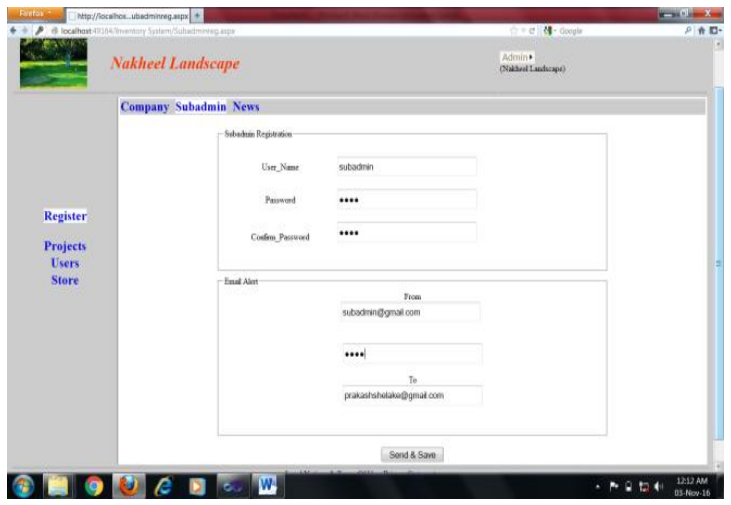

Fig 5. Company Registration

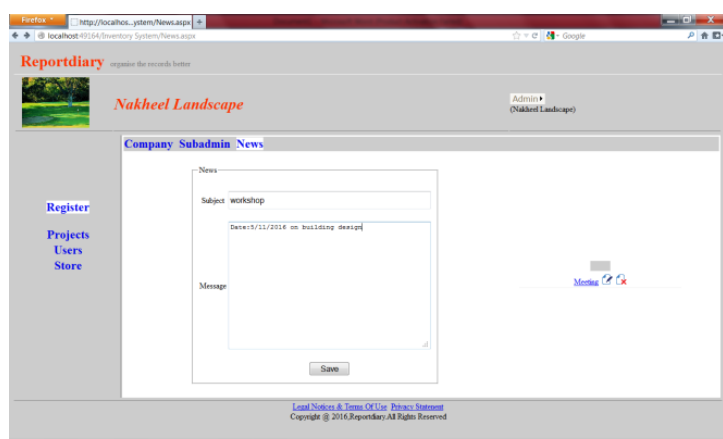

(9) De E D a w

Fig 6. News Feeding

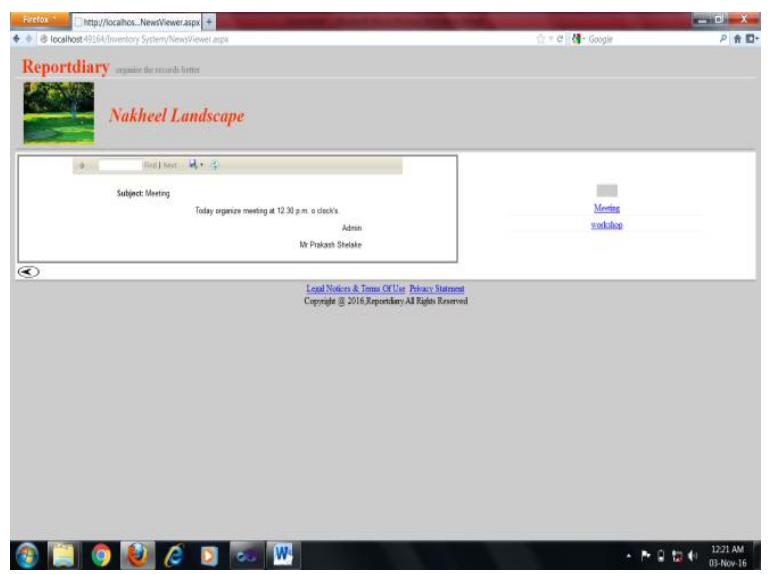

Fig 7. News Viewer

\section{VI.CONCLUSION}

This is "Web Based Inventory System" which is useful for Construction Company to making smart or digitalized work to increase work progress. This project contain maintain the inventory of the particular site and maintain stock.

\section{ACKNOWLEDGEMENT}

It is our privilege to acknowledge with deep sense of gratitude to our project guide Prof. Mahind R.N. and our Head Of Department Prof. Patil A. N. whose supervision, inspiration and valuable discussion has helped us tremendously to complete our project. Their guidance proved to be the most valuable to overcome all the hurdles in the fulfilment for the project.

\section{REFERENCES}

1) "Web-Based Inventory Management System for the West Virginia State Police" by Robert M. Horwatt 2007

2) Syed Jamal Abdul Nasir bin Syed Mohamad, Nurul Nadia Suraidi, Nabihah Amirah Abd. Rahman, and Raja Durratun Sakinah Raja Suhaimi "A Study on Relationship between Inventory Management and Company Performance: A Case Study of Textile Chain Store" July 2016

3) Tom Jose V, Akhilesh Jayakumar, Sijo M T" Analysis of Inventory Control Techniques: A Comparative Study" March 2013.

4) Abisoye Opeyemi A., Boboye Fatoba, Abisoye Blessing O "Design of a Computerized Inventory Management System for Supermarkets" September 2013

5) Toktay, Wein and Zenios "Inventory Management of Remanufacturable Products" June 1997

6) Serhii ZIUKOV" A LITERATURE REVIEW ON MODELS OF INVENTORY MANAGEMENT UNDER UNCERTAINTY" 2015 